\title{
Universal scaling of human flow remain unchanged during the COVID-19 pandemic
}

Yohei Shida' ${ }^{1}$, Hideki Takayasu²,3, Shlomo Havlin ${ }^{4,5}$ and Misako Takayasu ${ }^{1,3^{*}}$ (1)

*Correspondence:

takayasu.m.aa@m.titech.ac.jp

${ }^{3}$ Institute of Innovative

Research, Tokyo Institute

of Technology, Yokohama,

Japan

Full list of author information is available at the end of the article

\begin{abstract}
To prevent the spread of the COVID-19 pandemic, governments in various countries have severely restricted the movement of people. The large amount of detailed human location data obtained from mobile phone users is useful for understanding the change of flow patterns of people under the effect of pandemic. In this paper, we observe the synchronized human flow during the COVID-19 pandemic using Global Positioning System data of about 1 million people obtained from mobile phone users. We apply the drainage basin analysis method which we introduced earlier for characterization of macroscopic human flow patterns to observe the effect of the spreading pandemic. Before the pandemic the afternoon basin size distribution has been approximated by an exponential distribution, however, the distribution of Tokyo and Sapporo, which were most affected by the first wave of COVID-19, deviated significantly from the exponential distribution. On the other hand, during the morning rush hour, the scaling law holds universally, i.e., in all cities, even though the number of moving people in the basin has decreased significantly. The fact that these scaling laws, which are closely related to the three-dimensionality structure of the city and the fractal structure of the transportation network, have not changed indicates that the macroscopic human flow features are determined mainly by the means of transport and the basic structure of cities which are invariant of the pandemic.
\end{abstract}

Keywords: GPS data, City structure, Power law, Scaling relations

\section{Introduction}

Since the initial case of infection was confirmed at the end of 2019 https://www.who.int/ emergencies/diseases/novel-coronavirus-2019/events-as-they-happen, COVID-19 pandemic has been spreading rapidly all over the world https://covid19.who.int/ and seriously affecting the entire socio-economy such as finance (Goodell 2020; Ashraf 2020), education (Marinoni et al. 2020; Pragholapati 2020) and people's taste (Ding et al. 2020). As it is well known, human movement play a crucial role in the spread of infection (Tizzoni et al. 2014; Viboud et al. 2006; Balcan et al. 2009; Hufnagel et al. 2004; Colizza et al. 2007; Giles et al. 2020; Gross et al. 2020), and many governments have blockaded cities and restricted individual mobility. Evaluation of human mobility using individuals location data has been studied for Italy during spreading of COVID-19 (Pepe et al. 2020), and there exist many studies, focusing on the changes in human mobility patterns due author(s) and the source, provide a link to the Creative Commons licence, and indicate if changes were made. The images or other third party material in this article are included in the article's Creative Commons licence, unless indicated otherwise in a credit line to the material. If material is not included in the article's Creative Commons licence and your intended use is not permitted by statutory regulation or exceeds the permitted use, you will need to obtain permission directly from the copyright holder. To view a copy of this licence, visit http:// creativecommons.org/licenses/by/4.0/. 
to the effects of stay-at-home order in each country (Jeffrey et al. 2020; Lutu et al. 2020; Gao et al. 2020; Huang et al. 2020; Yabe et al. 2020; Bonaccorsi et al. 2020; Engle et al. 2020; Jia et al. 2020; Orro et al. 2020). In the United Kingdom, the mobility of people after the Prime Minister's announcement of an enforced lockdown has decreased significantly (Jeffrey et al. 2020). There has been found a slight difference in the median number of trips between high population density areas and low population density areas, which reflect a decrease in the number of people heading to the city center. In Italy's national lockdown, the relationship between economic variables and mobility change has been reported, and the results suggest that the lockdown unequally influences the poor (Bonaccorsi et al. 2020). In the United States, the human mobility during the pandemic has decreased significantly on average, but there was a temporarily marked increase in mobility due to the protest demonstration against racism that began with the death of Mr. George Floyd (Huang et al. 2020). In Japan, the number of railway users has decreased significantly, and since the declaration of emergency, the number of station users during peak hours in April and May has declined by $70 \%$ compared to normal times https://www.mlit.go.jp/tetudo/tetudo_fr1_000062.html. Despite the noncompulsory measures, the radius of gyration decreased to $50 \%$ of the typical and the social contact index reached 30\% of normal times by April 15th (Yabe et al. 2020).

In this paper, we analyze human movement patterns during the COVID-19 pandemic from a new viewpoint that focuses on synchronized human flow patterns rather than individual trajectories. Recently, we have developed and applied a new concept of drainage basins analysis in analogous to river flow patterns (Takayasu and Inaoka 1992) to GPS data of 2015 and revealed several universal scaling laws about human flow patterns around big cities (Shida et al. 2020). In contrast to the uncorrelated flow patterns in the afternoon, there are strong flows towards the city center from suburban areas in the morning, and inherent new universal laws of the human flows have been discovered which can be characterized and understood by the 3-dimensional structure of central city buildings and the fractal structure of main transport links. Here, we compare the results of the human flow pattern under the effect of COVID-19 pandemic with the analysis results in the 2015 data (Shida et al. 2020) before the spreading of COVID-19 pandemic.

\section{Results}

\section{The data}

The GPS data was purchased from a Japanese private company https://www.agoop.co.jp/ en/. We analyzed the data for all days in 2020. The data consist of user ID, time, latitude, longitude, speed, and direction. The number of users is about 1 million with intervals of data transmission mostly less than $10 \mathrm{~min}$. For protection of privacy, the data transmission stops in the midnight and the user ID is re-newed every day.

\section{The impact of emergency state issued in Japan}

The declaration of emergency state issued in Japan for COVID-19 from April 7th to May 25th severely restricted the movement of people. In Fig. 1a-c, we show the monthly population distribution on weekdays of moving people in the morning (07:30-08:00) around the Tokyo metropolitan area, in three different months. 


\section{a}

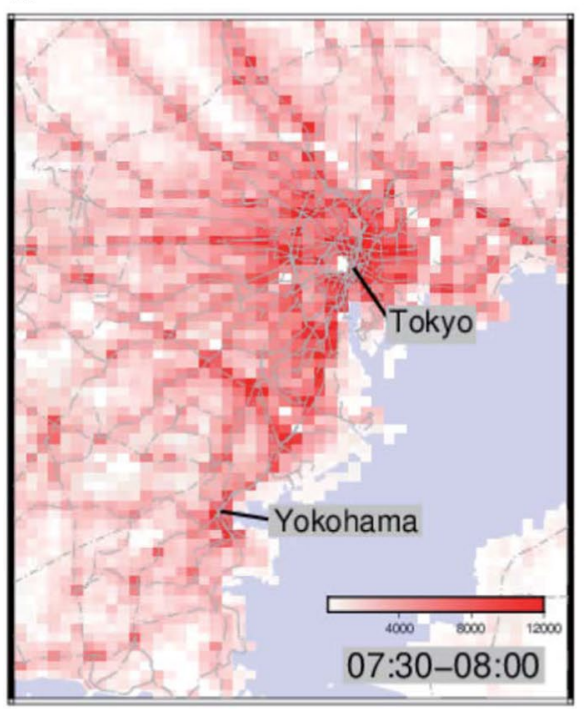

$\mathrm{b}$

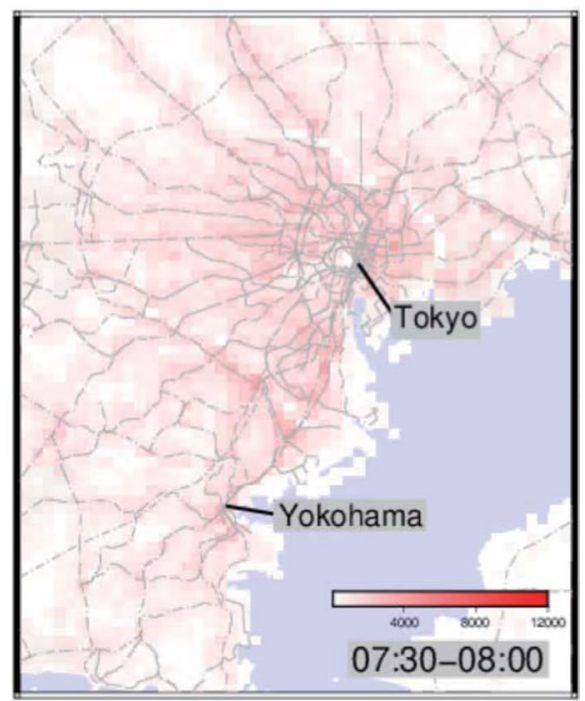

C

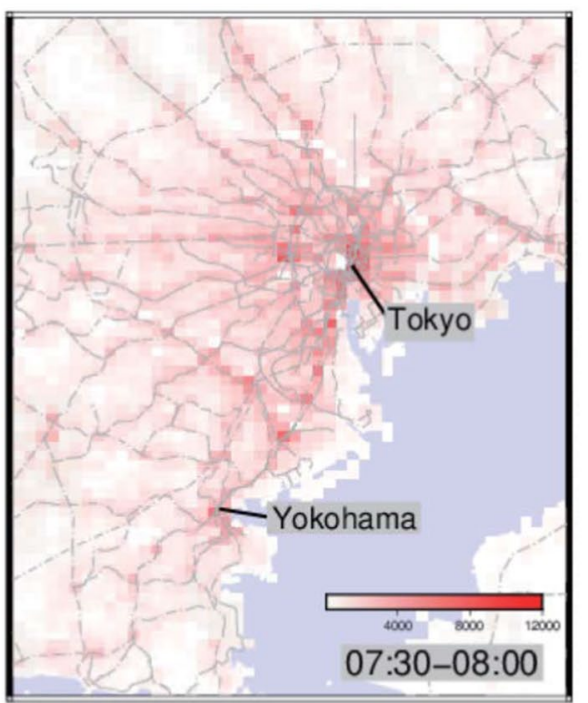

Fig. 1 The population distribution of moving people in the morning around the Tokyo metropolitan area. $\mathbf{a}-\mathbf{c}$, Population distribution maps of moving people in the morning on weekdays in January (a), May (b), and October (c), where the predicted population is normalized to the actual population in Japan with color strength proportional to the number of moving people in the square. The total number of moving people in the morning (07:30-08:00) is 9,000,000 (January), 2,500,000 (May), 3,300,000 (October) in the Tokyo metropolitan area, whose population is 35,000,000 (Tokyo, Kanagawa, Saitama, Chiba). The gray lines in the map represent the railways

In contrast to the intense commuter rush in January, we can see that the number of moving people in May has decreased significantly. The population in each square has decreased by about $70 \%$ on average, indicating that many people chose telework. In October, the movement of people has revived a little. This is probably because some companies have canceled telework due to reasons such as business productivity and poor internal communication https://www.tokyo-cci.or.jp/page.jsp?id=1023286. 


\section{Drainage basin structures under the effect of COVID-19 pandemic}

We apply the drainage basin analysis method that has been developed by us Shida et al. (2020) to characterize the human flow patterns during the COVID-19 pandemic, where the analysis range is from April 7 to June 30, 2020 on weekdays, after the state of emergency was announced. Our basin analysis is very simple (Shida et al. 2020). First, in Fig. 2a, b, we divide the map into squares of $500 \mathrm{~m} \times 500 \mathrm{~m}$ square in time intervals of $30 \mathrm{~min}$ (5:00-24:00) and calculate the mean velocity vector and the population of moving people in each square. Next, in analogy to river analysis (Shida et al. 2020), we perform the operation of connecting to one of the four adjacent sections according to the direction of the velocity vector of each square. This operation is applied to all squares, and the drainage basin cluster is uniquely determined.

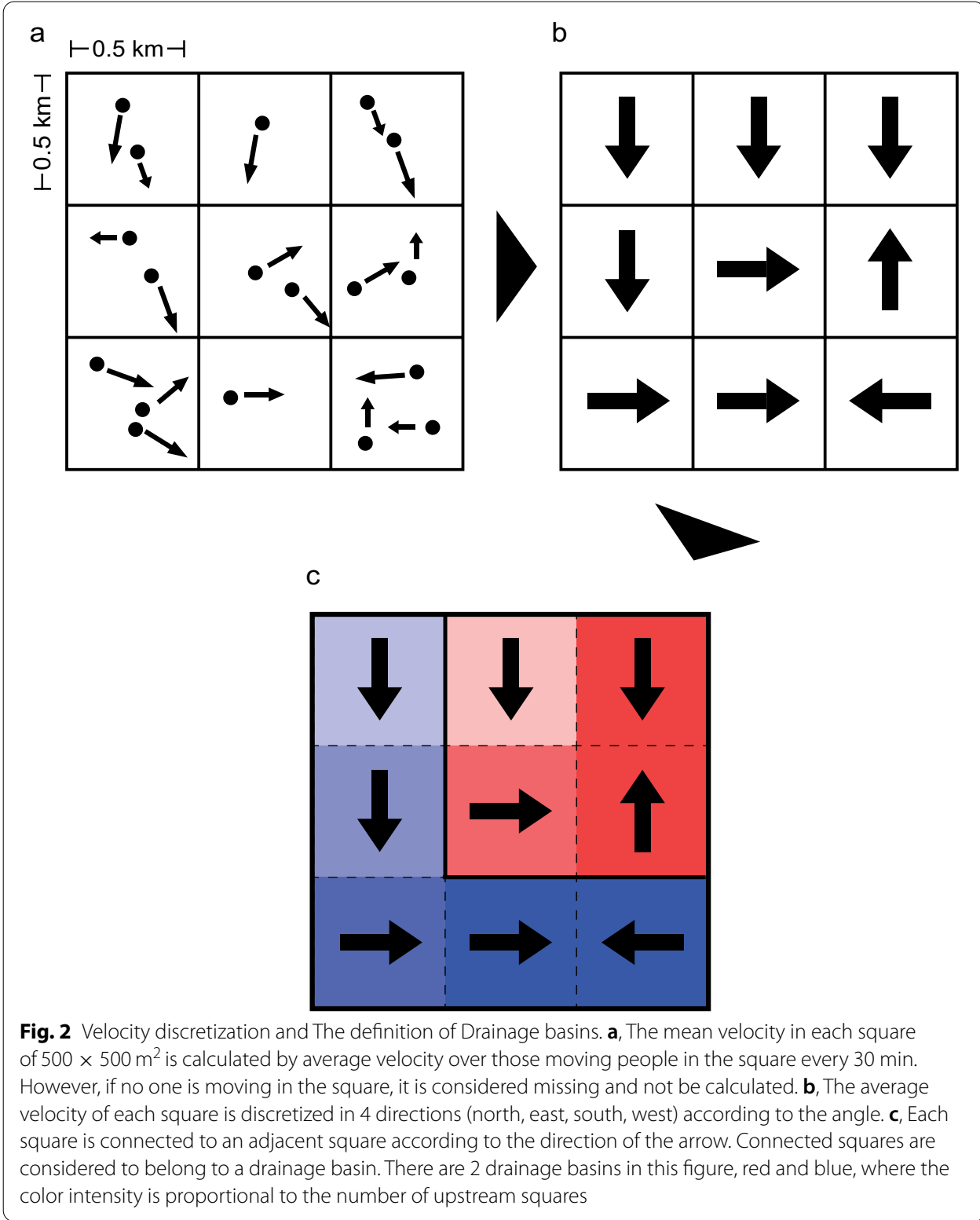


Figure 2c shows an example of creating a simple drainage basins. It is possible to divide the focusing area into each basin and further investigate its internal structure. By this operation, it is possible to divide the human flow into several basin clusters, and if there is a flow towards the city center, for example, a huge basin is expected to appear.

Figure 3a, b are top 15 basins drawn in the Tokyo metropolitan area in the morning and noon, where dark squares mean that they are located downstream in the basin. In the morning, we can see that huge basins appear around the center of Tokyo. The basins in the daytime are smaller than the morning basins. At first glance, the pattern of basins look similar to the random patterns observed before the spreading of COVID-19 pandemic, but we can see that the basins are more heading toward the center of Tokyo.

To understand these size differences, we apply the same drainage basin analysis for the nine metropolitan areas of Japan and focus on the size distribution. Figure 4a, b show the cumulative distribution function (CDF) in the morning and noon, respectively. The $y$-axis shows the cumulative distribution and the $\mathrm{x}$-axis shows the basin size normalized by the mean basin size. The size distributions in the morning are straight lines on the log-log plot and can be approximated by a power law with an exponent value of about 2.4 which are similar to those found in normal times. It can be seen that the basin size distributions of Tokyo and Sapporo in the daytime deviate significantly from a straight line, which is very different from the simulation results (dotted lines). Tokyo and Sapporo took the most amount of time to lift their emergency declarations https://www3.nhk.or.jp/nhkworld/en/news/backstories/1109/, meaning that those cities most affected by COVID-19. The weak directed human flow in Tokyo and Sapporo, which is different from random in the daytime, is probably due to the staggered commuting hours to avoid the infection caused by congestion.

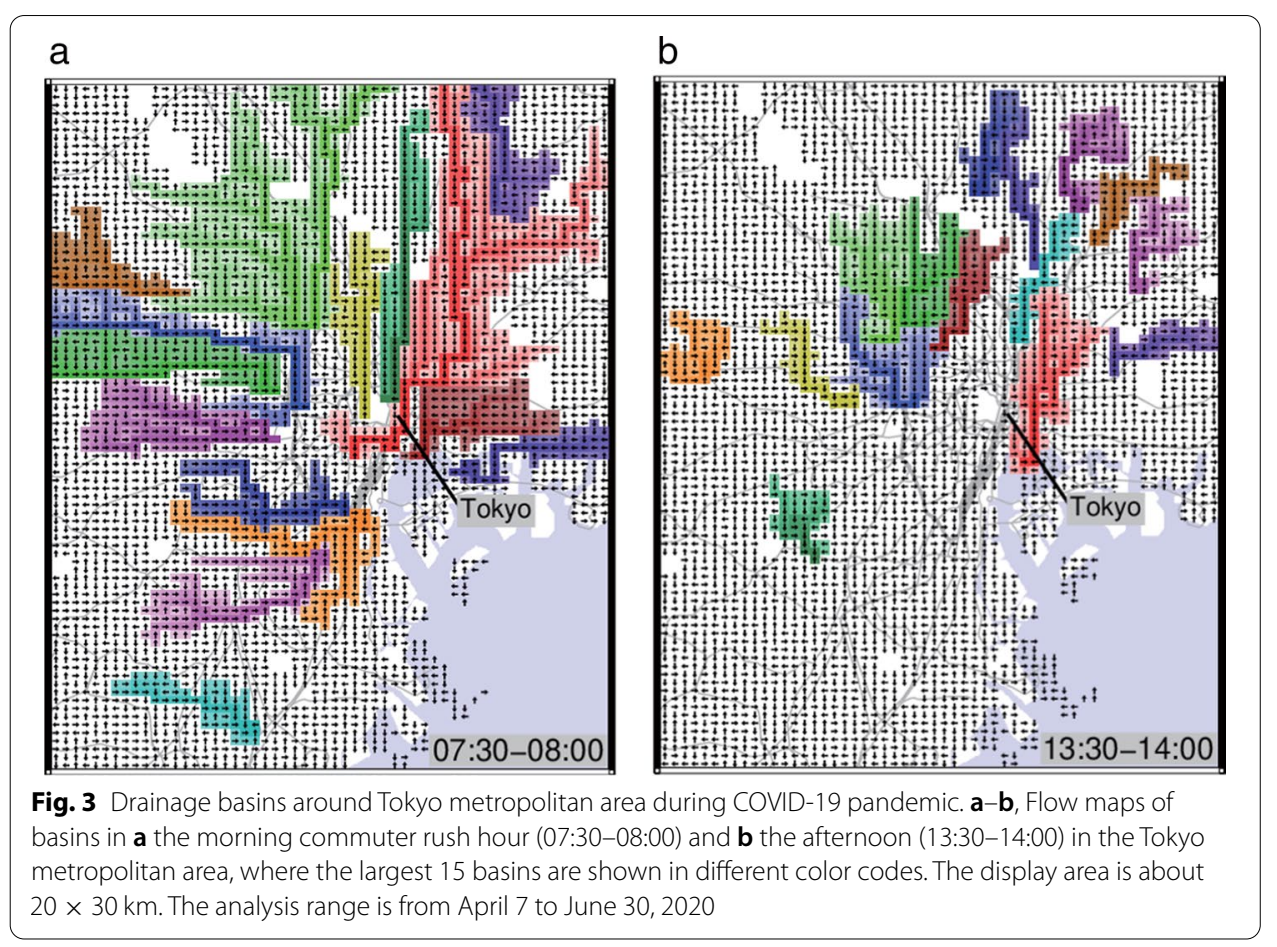



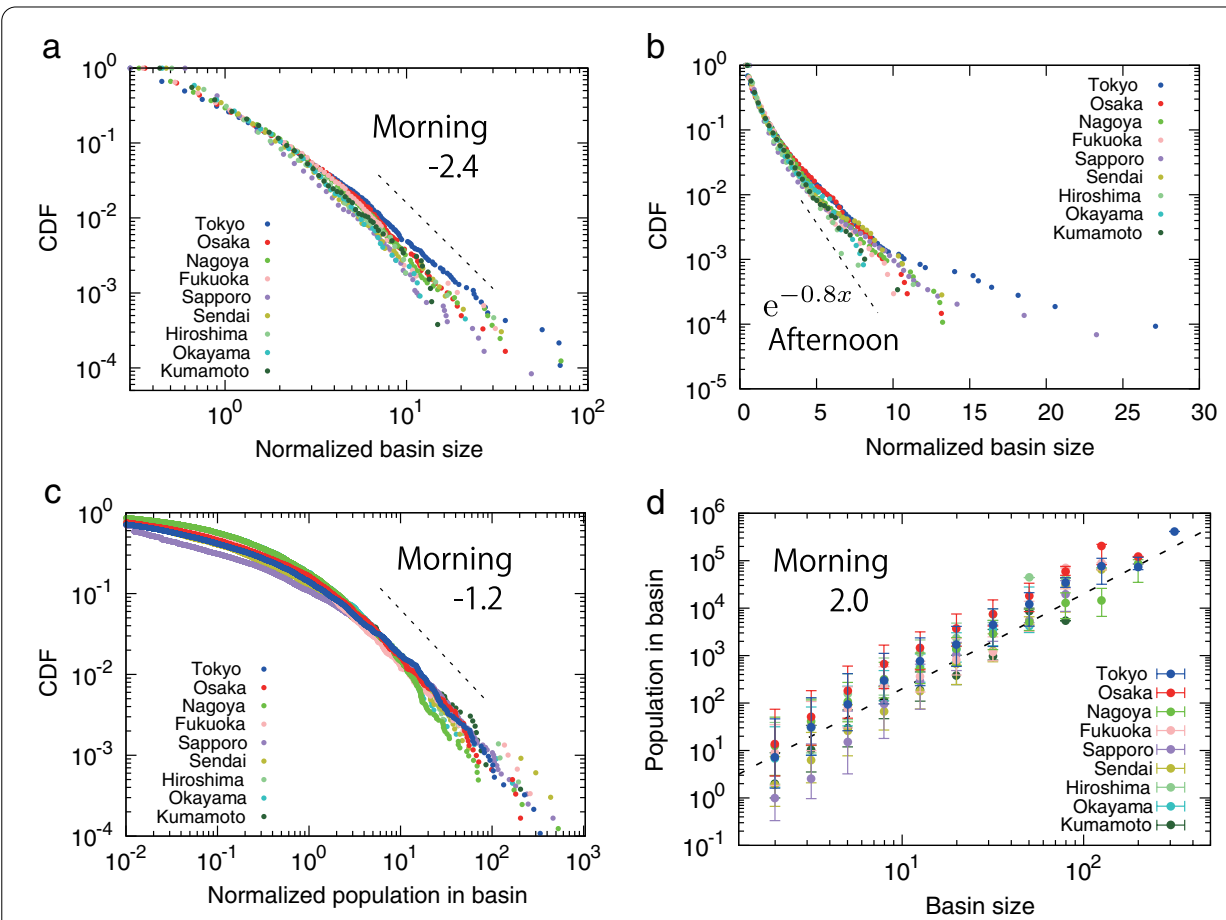

Fig. 4 Cumulative distribution function (CDF) of basin size and population distributions for 9 cities during COVID-19 pandemic. a, CDFs of basin sizes in the morning rush hour for the 9 analyzed cities (Tokyo, Osaka, Nagoya, Fukuoka, Sapporo, Sendai, Hiroshima, Okayama and Kumamoto) during COVID-19 (from April 7 to June 30,2020), where basin sizes are normalized by the mean basin size. We prepare human flow that accumulates weekday data from April 7th to June 30th, 2020, and calculate drainage basins. CDFs of the morning commuter rush hour are approximated by a power distribution of the same exponent -2.4 as before the spreading of COVID-19 pandemic (Shida et al. 2020). b. The afternoon size distribution during COVID-19 pandemic. Comparing with the same plots for the year of 2016 before the pandemic shown in Fig. 8b, the distributions have longer tails deviating clearly for Tokyo and Sapporo. c, In the morning rush hours, CDFs of population of moving people in the basin follow a power distribution of exponents -1.2, where the population in the basin is normalized by the average population in basins. This is again similar to that found in the non-pandemic times (Shida et al. 2020). d, The number of people moving in the basin during the morning rush hours is proportional to the square of the size of the basin

Next, we focus on the number of moving people in the basin during the morning hours. Figure $4 \mathrm{c}$ shows that the cumulative distributions of the number of moving people can be approximated by a power law with an exponent value close to 1.2. Figure 1 shows that the number of moving people has decreased significantly due to the COVID-19 pandemic, but surprisingly, the distributions of moving people in each basin have similar power law exponents as before the spreading of COVID-19 pandemic. This suggests that the reduced number of people in each grid is roughly the same fraction of (0.7) each grid. This indicates that the shrink of moving people was uniform, with almost the same fraction. From these power law exponents, the relationship between the size $S_{b}$ and the number of moving people $p_{b}$ in the b-th basin is given as:

$$
p_{b} \propto S_{b}^{2}
$$


which is invariant although population density decreased. This relationship can be confirmed directly from Fig. 4d.

\section{Fractal structures}

Next, we calculate the diameter $L_{b}$ of the basin, $b$, and confirm the universality of the structure of the basin. The diameter $L_{b}$ is defined by the maximum distance between two points in each basin. Figure $5 \mathrm{a}$ indicates a size $S_{b}$ is proportional to the diameter $L_{b}$ to the power of 1.5. Using the fractal measure relations (Takayasu 1990), we can estimate the fractal dimension of the basin size. Since the size of the basin is considered to be closely related to the railway and road network, the fractal property does not change despite the significant decrease in the number of people in movement. Furthermore, in Fig.5b, the population of moving people in the basin $p_{b}$ is also proportional to the diameter $L_{b}$ cube, and the three-dimensionality of the city remains maintained. Since it takes many years and labor to change the structure of the city, it is reasonable that the threedimensional structure of the city did not change during the COVID-19 pandemic. That is, the following relationship

$$
L_{b} \propto p_{b}^{\frac{1}{3}} \propto S_{b}^{\frac{1}{1.5}}
$$

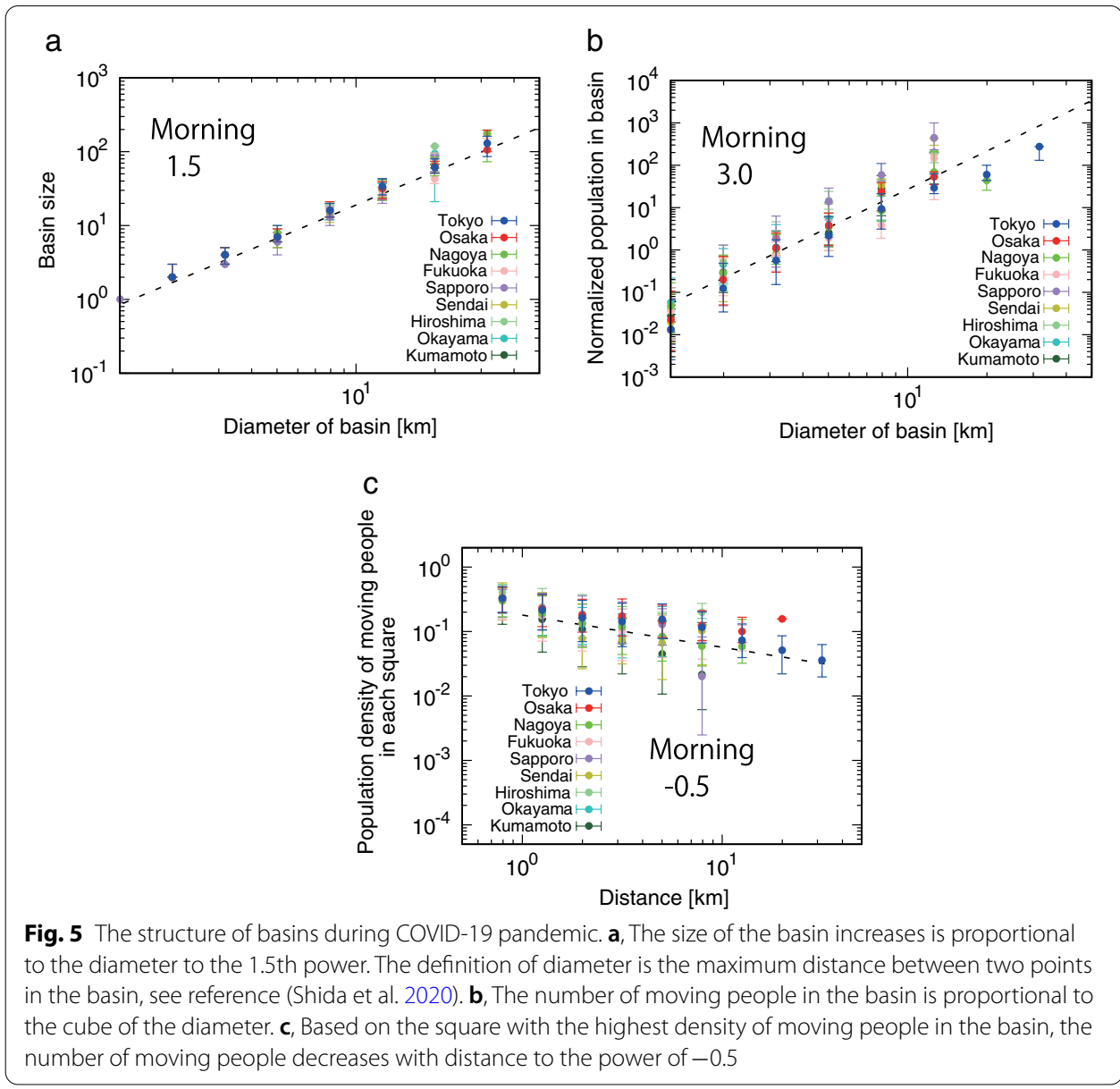




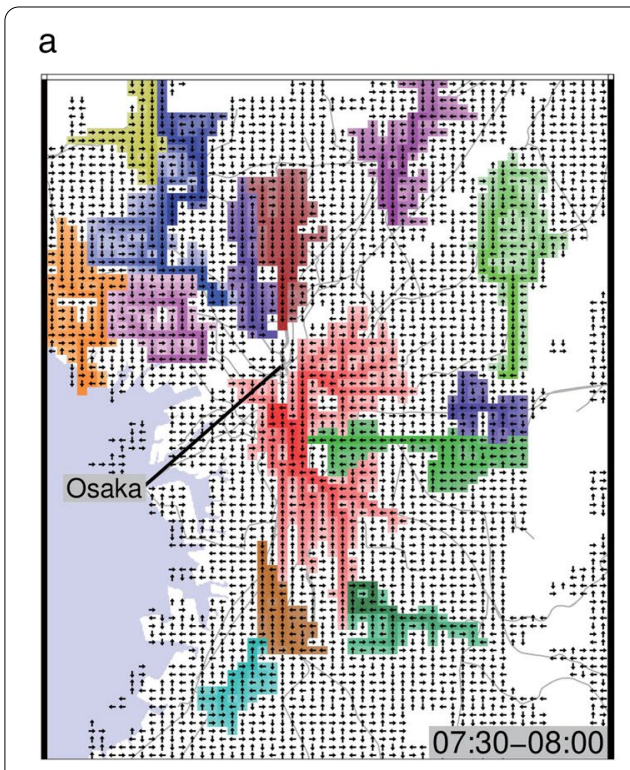

b
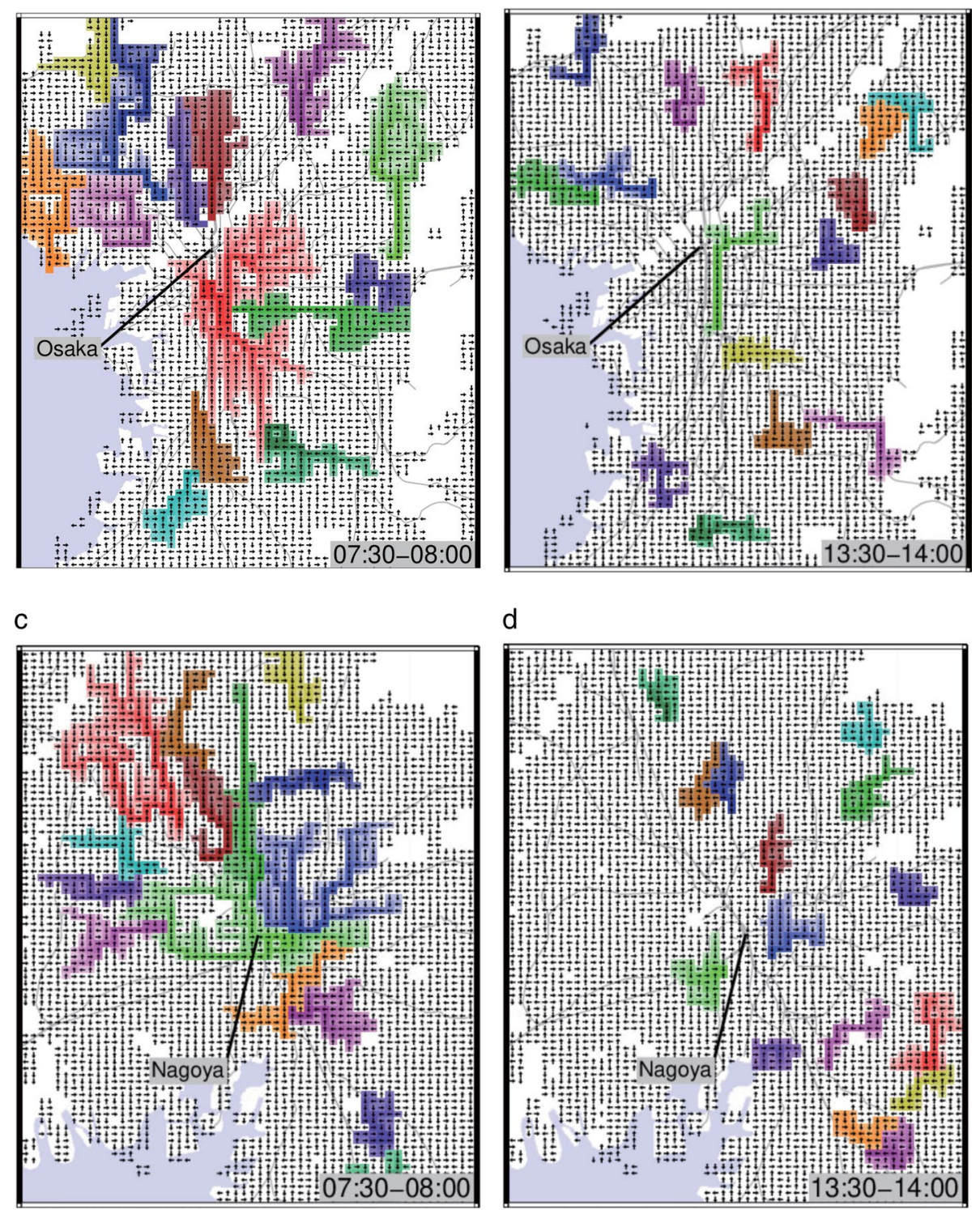

d

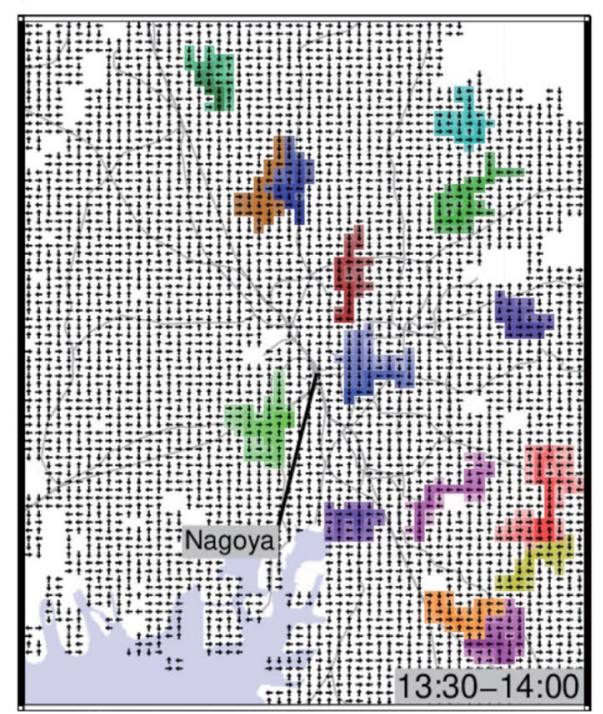

Fig. 6 Drainage basins around Osaka and Nagoya metropolitan area during COVID-19 pandemic. a, b, Flow maps of basins in $\mathbf{a}$ the morning commuter rush hour (07:30-08:00) and $\mathbf{b}$ the afternoon (13:30-14:00) in the Osaka metropolitan area, where the largest 15 basins are shown in different color codes. The display area is about 20-30 km square. c-d, Flow maps of basins in a the morning commuter rush hour (07:30-08:00) and b the afternoon (13:30-14:00) in the Nagoya metropolitan area, where the largest 15 basins are shown in different color codes. The display area is about $20-30 \mathrm{~km}$ square

holds unchanged between the diameter $L_{b}$, size $S_{b}$, and population $p_{b}$ of the basin, despite the significant reduction in the number of moving people to prevent the spread of infection. Finally, in Fig. 5c, we show the relation between population of moving people as a function of distance $r$ from the most populated square to reveal the population 


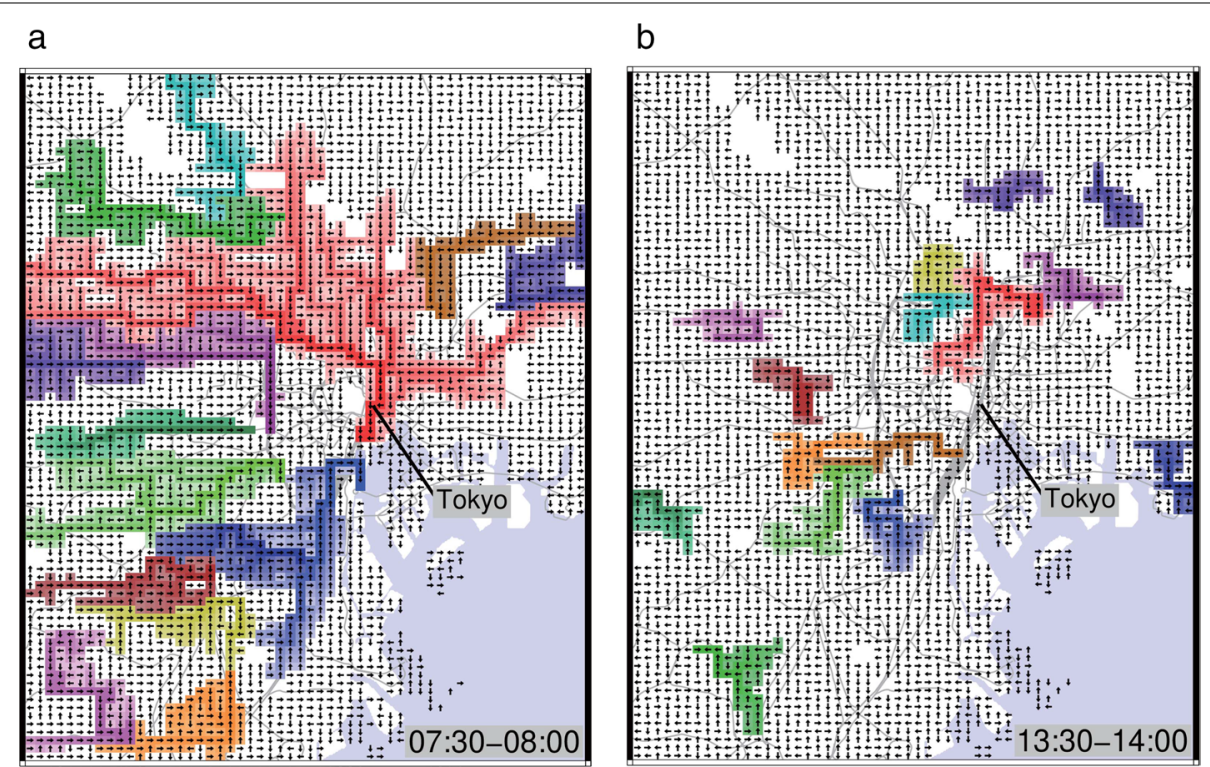

Fig. 7 Drainage basins around Tokyo metropolitan area in the year 2016. $\mathbf{a}$, b. Flow maps of basins in $\mathbf{a}$ the morning commuter rush hour (07:30-08:00) and $\mathbf{b}$ the afternoon (13:30-14:00) in the Tokyo metropolitan area, where the largest 15 basins are shown in different color codes. The display area is about 20-30 km square. The analysis range is the whole year of weekday 2016

distribution in each basin. The population of moving people in each square is found to be inversely proportional to the square root of the distance $r$. This is the same exponent as found before the spreading of COVID-19 pandemic, meaning that the government's declaration of a state of emergency resulted in a uniform voluntary restraint regardless of the region.

\section{Conclusion}

In summary we analyzed the human flow patterns in 9 urban areas in Japan under the COVID-19 pandemic expansion based on the drainage basin analysis of GPS data. Before the pandemic the afternoon basin size distribution was approximated by an exponential distribution, which indicate random movements, however, the distribution of Tokyo and Sapporo deviates significantly from the exponential distribution in the period of government's declaration of a state of emergency caused by the COVID19 pandemic. This deviation is probably caused by people's choice not to travel at peak time in order to avoid congestion. On the other hand, during the morning rush hour, the scaling laws hold universally, even though the number of moving people in the basin has decreased significantly. The fact that these scaling laws, which are closely related to the three-dimensionality of the city and the fractal structure of transportation links, have not changed is considered to indicate that the structure of the city has not changed in spite of movement restrictions conducted. Finally, considering the universality of population distribution within the basin may help prevent congestion. For example, if the arrival time is shifted according to the distance to the destination, the population 

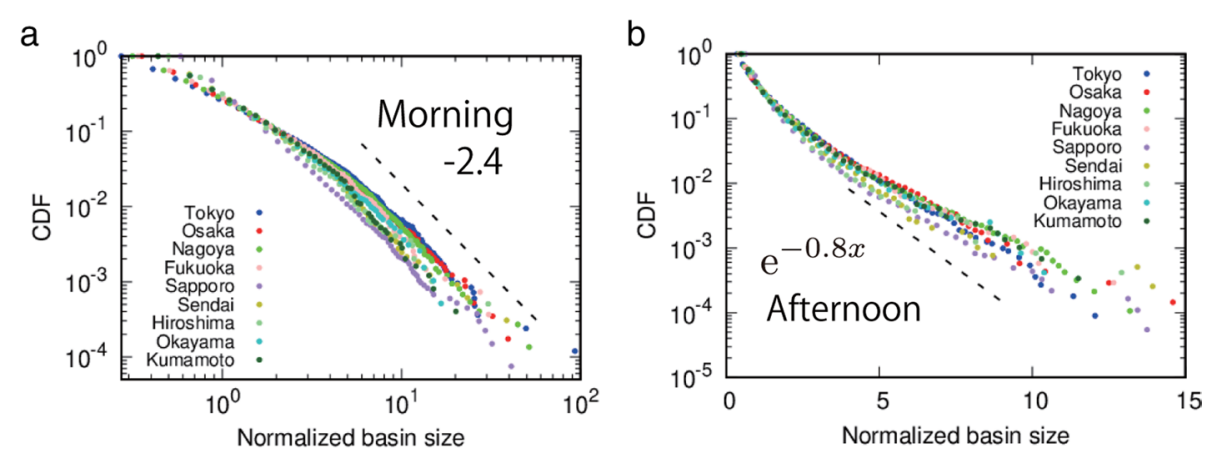

C

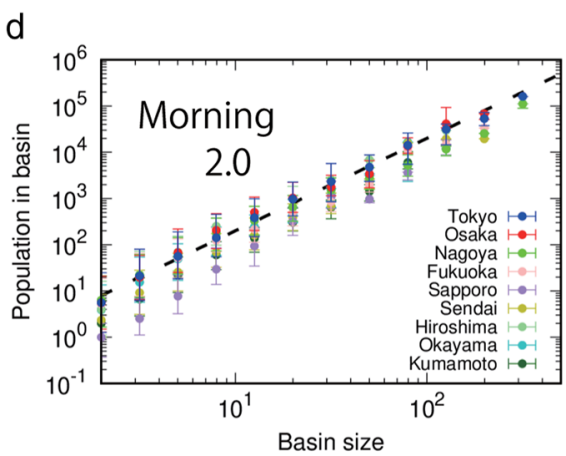

Fig. 8 CDF of basin size and population distributions for 9 cities in the year 2016. a, Morning and daytime basin size distribution in 9 cities (Tokyo, Osaka, Nagoya, Fukuoka, Sapporo, Sendai, Hiroshima, Okayama and Kumamoto), where the size definition is the number of combined squares. CDFs of the morning commuter rush hour are approximated with a power distribution of the exponent -2.4 . $\mathbf{b}$, The afternoon size distribution can be approximated by the exponential distribution (the dotted line). $\mathbf{c}$, In the morning rush hours, CDFs of population of moving people in the basin follow a power distribution of exponents -1.2 , where the population in the basin is normalized by the average population in basins. $\mathbf{d}$, The number of people moving in the basin during the morning rush hours is proportional to the square of the size of the basin. Note, (All results are consistent with those shown in Ref. Shida et al. (2020) for the year 2015.)

distribution of moving people in the basin is expected to change significantly. If it is possible to restrict movement for each individual based on GPS data, more efficient infection prevention measures may be possible.

\section{Appendix}

\section{Drainage basins around Osaka and Nagoya metropolitan area}

Figure 6 show the top 15 basins drawn in the Osaka and Nagoya metropolitan area in the morning and noon.

\section{Drainage basin structures in the year 2016 before the COVID-19 period}

For comparison with Figs. 3, 4 and 5, here we show Figs. 7, 8 and 9 which are produced by the same procedures applied for the whole year 2016 before the COVID-19. All results are consistent with those in Ref. Shida et al. (2020) for the year 2015. 


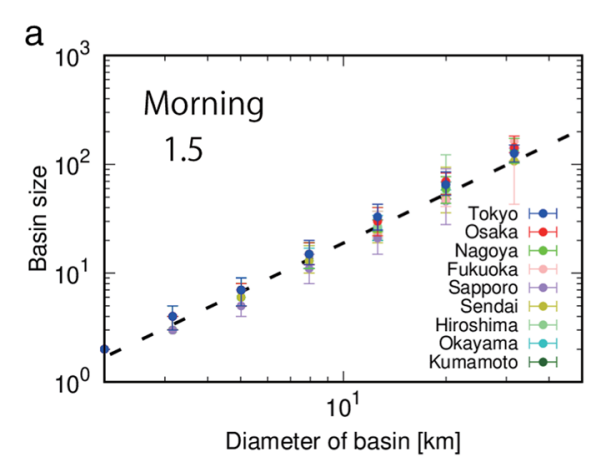

b
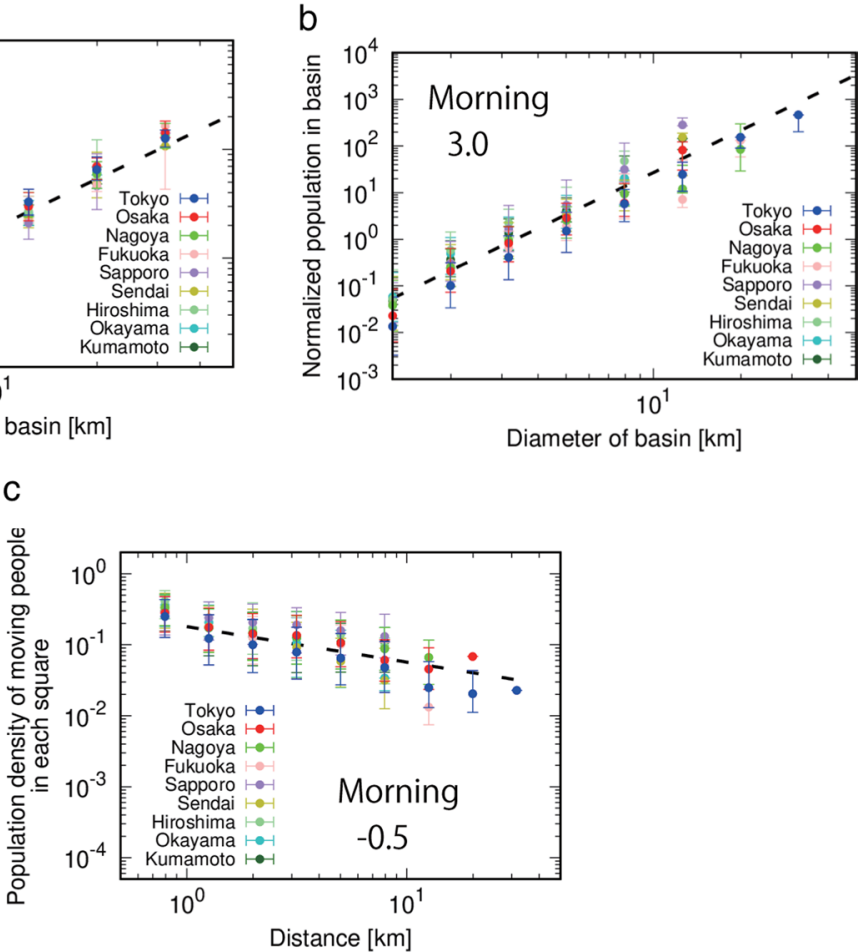

Fig. 9 The structure of basins in the year 2016. a, The size of the basin increases in proportion to the diameter to the 1.5th power. The definition of diameter is basin crossing, see the paper Shida et al. (2020). $\mathbf{b}$, The number of moving people in the basin is proportional to the cube of the diameter. $\mathbf{c}$, Based on the square with the highest density of moving people in the basin, the number of moving people decreases to the power of -0.5

\section{Abbreviations}

GPS: Global positioning system; CDF: Cumulative distribution function.

\section{Acknowledgements}

We thank Agoop for providing the GPS datasets. This work was supported by Tokyo Tech World Research Hub Initiative (WRHI) Program of Institute of Innovative Research, Tokyo Institute of Technology.

\section{Authors' contributions}

MT was the leader of this project, designed the whole research plan and directed writing of the manuscript. YS analyzed the raw data, performed the numerical calculations, and wrote the manuscript. HT and SH developed methods of data analysis and revised the manuscript. All authors read and approved the final manuscript.

\section{Funding}

This work was supported by Grant-in-Aid for Scientific Research (B), Grant Number 18H01656. S.H. thanks the Israel Science Foundation, (Grant No. 189/19) and the joint China-Israel Science Foundation (Grant No. 3132/19), ONR, the Japan Science Foundation with MOST, BSF-NSF, ARO, the BIU Center for Research in Applied Cryptography and Cyber Security, and DTRA (Grant No. HDTRA-1-19-1-0016) for financial support.

\section{Availability of data and materials}

Our data cannot be open to public, but the same data can be purchased from a Japanese private company, https:// www.agoop.co.jp/en/, which sells "The location information big data which acquired from the smart phone app."

\section{Declarations}

\section{Ethics approval and consent to participate}

The GPS data we analyzed are anonymized and no personal information is included. Our analyses focus on macroscopic human flow patterns, so there is no need for informed consent. 


\section{Competing interests}

The authors declare that they have no competing interests.

\section{Author details}

${ }^{1}$ Department of Mathematical and Computing Science, School of Computing, Tokyo Institute of Technology, Yokohama, Japan. ${ }^{2}$ Sony Computer Science Laboratories, Tokyo, Japan. ${ }^{3}$ Institute of Innovative Research, Tokyo Institute of Technology, Yokohama, Japan. ${ }^{4}$ Department of Physics, Bar-llan University, Ramat-Gan, Israel. ${ }^{5}$ Tokyo Tech World Research Hub Initiative (WRHI), Institute of Innovative Research, Tokyo Institute of Technology, Yokohama, Japan.

Received: 27 April 2021 Accepted: 11 September 2021

Published online: 10 October 2021

\section{References}

Agoop. https://www.agoop.co.jp/en/. Accessed 16 Feb 2021

Ashraf BN (2020) Economic impact of government interventions during the COVID-19 pandemic: international evidence from financial markets. J Behav Exp Finance 27:100371

Balcan D, Colizza V, Gonçalves B, Hu H, Ramasco JJ, Vespignani A (2009) Multiscale mobility networks and the spatial spreading of infectious diseases. Proc Natl Acad Sci 106(51):21484-21489

Bonaccorsi G, Pierri F, Cinelli M, Flori A, Galeazzi A, Porcelli F, Schmidt AL, Valensise CM, Scala A, Quattrociocchi W et al (2020) Economic and social consequences of human mobility restrictions under COVID-19. Proc Natl Acad Sci 117(27):15530-15535

Colizza V, Barrat A, Barthelemy M, Valleron A-J, Vespignani A (2007) Modeling the worldwide spread of pandemic influenza: baseline case and containment interventions. PLoS Med 4(1):13

Coronavirus (COVID-19) events as they happen. https://www.who.int/emergencies/diseases/novel-coronavirus-2019/ events-as-they-happen. Accessed 26 Dec 2020

Ding D, del Pozo Cruz B, Green MA, Bauman AE (2020) Is the COVID-19 lockdown nudging people to be more active: a big data analysis. BMJ Publishing Group Ltd and British Association of Sport and Exercise Medicine, London

Engle S, Stromme J, Zhou A (2020) Staying at home: mobility effects of COVID-19. Available at SSRN

Gao S, Rao J, Kang Y, Liang Y, Kruse J, Dopfer D, Sethi AK, Reyes JFM, Yandell BS, Patz JA (2020) Association of mobile phone location data indications of travel and stay-at-home mandates with COVID-19 infection rates in the US. JAMA Netw Open 3(9):2020485

Giles JR, zu Erbach-Schoenberg E, Tatem AJ, Gardner L, Bjørnstad ON, Metcalf C, Wesolowski A (2020) The duration of travel impacts the spatial dynamics of infectious diseases. Proc Natl Acad Sci 117(36):22572-22579

Goodell JW (2020) COVID-19 and finance: agendas for future research. Finance Res Lett 35:101512

Gross B, Zheng Z, Liu S, Chen X, Sela A, Li J, Li D, Havlin S (2020) Spatio-temporal propagation of COVID-19 pandemics. Europhys Lett EPL 131(5):58003

Huang X, Li Z, Jiang Y, Li X, Porter D (2020) Twitter reveals human mobility dynamics during the COVID-19 pandemic. PLOS ONE 15(11):0241957

Hufnagel L, Brockmann D, Geisel T (2004) Forecast and control of epidemics in a globalized world. Proc Natl Acad Sci 101(42):15124-15129

Japan lifts state of emergency for Tokyo, four remaining prefectures—NHKWORLD-JAPAN News. https://www3.nhk.or.jp/ nhkworld/en/news/backstories/1109/. Accessed 12 July 2021

Jeffrey B, Walters CE, Ainslie KEC et al. (2020) Anonymised and aggregated crowd level mobility data from mobile phones suggests that initial compliance with COVID-19 social distancing interventions was high and geographically consistent across the UK. Wellcome Open Res 5:170. https://doi.org/10.12688/wellcomeopenres.15997.1

Jia JS, Lu X, Yuan Y, Xu G, Jia J, Christakis NA (2020) Population flow drives spatio-temporal distribution of COVID-19 in China. Nature 582(7812):389-394

Lutu A, Perino D, Bagnulo M, Frias-Martinez E, Khangosstar J (2020) A characterization of the COVID-19 pandemic impact on a mobile network operator traffic. In: Proceedings of the ACM internet measurement conference. pp 19-33

Marinoni G, Van't Land H, Jensen T (2020) The impact of COVID-19 on higher education around the world. IAU Global Survey Report

Orro A, Novales M, Monteagudo Á, Pérez-López J-B, Bugarín MR (2020) Impact on city bus transit services of the COVID19 lockdown and return to the new normal: the case of a coruña (Spain). Sustainability 12(17):7206

Pepe E, Bajardi P, Gauvin L, Privitera F, Lake B, Cattuto C, Tizzoni M (2020) COVID-19 outbreak response, a dataset to assess mobility changes in Italy following national lockdown. Sci Data 7(1):1-7

Pragholapati A (2020) COVID-19 impact on students

Questionnaire on the implementation status of telework. https://www.tokyo-cci.or.jp/page.jsp?id=1023286. Accessed 02 Jan 2021

Shida Y, Takayasu H, Havlin S, Takayasu M (2020) Universal scaling laws of collective human flow patterns in urban regions. Sci Rep 10(1):1-10

Takayasu H (1990) Fractals in the physical sciences. Manchester University Press, Manchester

Takayasu H, Inaoka H (1992) New type of self-organized criticality in a model of erosion. Phys Rev Lett 68(7):966

Tizzoni M, Bajardi P, Decuyper A, King GKK, Schneider CM, Blondel V, Smoreda Z, González MC, Colizza V (2014) On the use of human mobility proxies for modeling epidemics. PLoS Comput Biol 10(7):1003716

To railway users (information for users of measures against new coronavirus infections): Ministry of Land, Infrastructure, Transport and Tourism. https://www.mlit.go.jp/tetudo/tetudo fr1 000062.html. Accessed 28 Dec 2020

Viboud C, Bjørnstad ON, Smith DL, Simonsen L, Miller MA, Grenfell BT (2006) Synchrony, waves, and spatial hierarchies in the spread of influenza. Science 312(5772):447-451 
WHO Coronavirus Disease (COVID-19) Dashboard—WHO Coronavirus Disease (COVID-19) Dashboard. https://covid19. who.int/. Accessed 26 Dec 2020

Yabe T, Tsubouchi K, Fujiwara N, Wada T, Sekimoto Y, Ukkusuri SV (2020) Non-compulsory measures sufficiently reduced human mobility in Tokyo during the COVID-19 epidemic. Sci Rep 10(1):1-9

\section{Publisher's Note}

Springer Nature remains neutral with regard to jurisdictional claims in published maps and institutional affiliations.

Submit your manuscript to a SpringerOpen ${ }^{\circ}$ journal and benefit from:

- Convenient online submission

- Rigorous peer review

- Open access: articles freely available online

- High visibility within the field

- Retaining the copyright to your article

Submit your next manuscript at $\boldsymbol{\nabla}$ springeropen.com 